\title{
A comparative clinical study of perineural administration of $0.75 \%$ ropivacaine with and without dexmedetomidinein upper limb surgery by ultrasound guided single injection supraclavicular brachial plexus block
}

\author{
Prashant Tiwari, Manish Jain*, Bhawana Rastogi, Salony aggarwal, Kumkum Gupta and VP Singh \\ Department of Anaesthesiology\& Critical Care Department in NSCB Subharti Medical College, Meerut (UP), India
}

\begin{abstract}
Many adjuvants to local anesthetic agents for brachial plexus block are investigated in an attempt to increase the onset and duration of block and to improve postoperative analgesia.The present study was designed to assess clinical utility of adding dexmedetomidine to local anesthetics during peripheral nerve blockade. 120 patients of age $18-58 \mathrm{yr}$, of either sex, of ASA grade I/II were randomized into two equal groups of 60 patients each, group R received $20 \mathrm{ml}$ of $0.75 \%$ ropivacaine with placebo while patients in group RD received $20 \mathrm{ml}$ of $0.75 \%$ ropivacaine with $50 \mu \mathrm{g}$ of dexmedetomidine for supraclavicular brachial plexus block using ultrasound guidance. Sensory and motor onset time, sensory and motor block duration, duration of analgesia, sedation scores, hemodynamic changes and any side effect were all recorded and statistically analyzed. Onset of sensory block ( $8.30 \pm 2.62 \mathrm{~min}$ vs $11.50 \pm 3.14 \mathrm{mins})$ and establishment of complete motor blockade (11.62 $\pm 3.39 \mathrm{~min} v s .15 .18 \pm 4.25 \mathrm{mins}$ ) were significantly earlier in the ropivacaine with dexmedetomidine group. Postoperative analgesia was prolonged significantly in the ropivacaine with dexmedetomidine group (1209.90 \pm 107.536 mins). In conclusion dexmedetomidine as adjuvant to $0.75 \%$ ropivacaine for supraclavicular brachial plexus block extends the duration of analgesia and shortened the onset time of sensory and motor block.
\end{abstract}

\section{Introduction}

Brachial plexus block is the most reliable and commonly preferred techniques for regional anesthesia of the upper extremity. The use of ultrasound guidance for nerve block has attained massive recognition in last few years. The concept of nerve visualisation by ultrasound is convincing and supported by literature [1-3]. Many adjuvants to local anesthetic agents are investigated including opioid [4-8] and nonopioid agents [9-11], in an attempt to increase the onset and duration of block and to improve post-operative analgesia. Clonidine, an $\alpha-2$ adrenergic agonist has been evaluated as an adjuvant to LA in brachial plexus block but dexmedetomidine, also an $\alpha-2$ adrenergic agonist has some advantageous characteristics compared to clonidine like greater hemodynamic stability as it is more selective for $\alpha 2$ adrenergic ( $\alpha 2: \alpha 1$ $=1620: 1$ ) [12] receptors and both baroreceptor reflexes and heart rate responses are well preserved with dexmedetomidine. However, there remains limited knowledge on the analgesic efficacy and clinical utility of adding dexmedetomidine to local anesthetics during peripheral nerve blockade in human population $[13,14]$. Therefore the present study was designed to evaluate the effect of adding dexmedetomidine to a $0.75 \%$ ropivacaine for ultrasound guided supraclavicular brachial plexus.

\section{Methods}

This prospective randomized double blind controlled study was conducted in Department of Anaesthesiology and Critical Care Medicine, Subharti Medical College, Meerut on 120 adult consented patients scheduled for elective unilateral upper limb (below shoulder) surgeries under ultrasound guided supraclavicular brachial plexus block. We compared the onset and duration of sensory and motor block, duration of analgesia, sedation level, hemodynamic changes and complications (if any). An approval from the Institutional committee of ethicsand written informed consent from patients were obtained. The present study was conducted on patients of both sexes, between 18-58 years of age, ASA grade I-II. The duration of operation was less than 90 minutes. Exclusion criteria included patients with chronic pain, those using chronic analgesic medications, coagulopathy, history of brachial plexus injury, allergy to the study drug, patients taking other medications with sympatholytic effects, hepatic or renal insufficiency, and infection at the site of injection, shoulder surgery and patient refusal. Complete pre anesthetic check-up was done and patients scheduled for elective surgery were admitted and a fasting of 6 hours was ensured. A total of 120 cards (for 60 in each group) were prepared byan anaesthesiologist who was blinded about the study and patients were grouped accordingly. Patients were randomized into two equal groups (group $\mathrm{R}$ and group $\mathrm{RD}$ ) of 60 patients each and patients in group $\mathrm{R}$ received $19 \mathrm{ml}$ of $0.75 \%$ ropivacaine with placebo (1 $\mathrm{ml}$ Normal saline) while patients in group $\mathrm{RD}$ received $19 \mathrm{ml}$ of $0.75 \%$ ropivacaine plus $50 \mu \mathrm{g}$ of dexmedetomidine ( $0.5 \mathrm{ml}$ plus $0.5 \mathrm{ml}$ Normal saline) for

Correspondence to: Jain M, Professor, Department of Anaesthesiology and Critical Care, Subharti Medical College, Meerut, Uttar Pradesh, India, Tel: +919837343693, Fax: +91-0121-2439056; E-mail: jainmanish45@yahoo.com

Key words: anesthetic, dexmedetomidine, ropivacaine

Received: September 18, 2015; Accepted: October 31, 2015; Published: November 03, 2015 
Tiwari P (2015) A comparative clinical study of perineural administration of $0.75 \%$ ropivacaine with and without dexmedetomidinein upper limb surgery by ultrasound guided single injection supraclavicular brachial plexus block

supraclavicular brachial plexus block using ultrasound guidance.

Patients were not premedicated before the Supraclavicular brachial plexus block. On arrival in the operating room, a venous access was established on the contralateral armand standard monitoring for BloodPressure, heart rate, pulse oximetry and ECG were commenced. All the blocks were performed by the same anaesthesiologist using transportable ultrasound system (Sonositemicromax, SonositeInc., Bothell, WA, USA) with a $38 \mathrm{~mm} 8-13 \mathrm{MHz}$ linear high frequency ultrasound transducer (HFL-38).

The study solution was prepared by an anaesthesiologist who was not aware about this study. The predetermined volume of the drug was administered around the brachial plexus after visualisation by ultrasound probe according to group $\mathrm{R}$ or group $\mathrm{RD}$ with a 22 gauge needle. Sensory block was confirmed by loss to cold sensation using an alcohol swab and pinprick sensation using a $25 \mathrm{G}$ hypodermic needle in all dermatomes of the brachial plexus (C5 - T1). Supraclavicular block was considered successful when all dermatomes of brachial plexus (C5 - T1) were blocked within 30 mins. Onset of sensory block was defined as a decrease of sensation to $25 \%$ or less by pinprick in comparison to contralateral limb as a reference. It was evaluated at $1,2,4,6,8,10$, 12 and $15 \mathrm{~min}$. and every five minutes thereafter until the effectivity or failure of the blockade was identified. Sensory block duration was defined as the time from injection of local anesthetic study solution to complete recovery from cold and pain sensation in all dermatomes of the brachial plexus.

Motor block onset was defined as the time from injection of local anesthetic study solution until achieving a reduction in motor power to grade $3 / 4$. It was evaluated at $1,2,4,6,8,10,12$ and $15 \mathrm{~min}$. and every five minutes thereafter until the effectivity or failure of the blockade is identified. Motor block duration was defined as the time interval between the end of LA mixture administration and the recovery of complete motor function of the hand and forearm of the blocked limb. Motor blockade was evaluated by motor blockade scale ${ }^{15}$ :-

Grade 1 -Ability to flex or extend the forearm

Grade 2-Ability to flex or extend only wrist or fingers

Grade 3-Ability to flex or extend only fingers

Grade 4-Inability to move the forearm, wrist or fingers

Blood pressure (Systolic, Diastolic and mean arterial pressures), Heart rates ,Peripheral Oxygen saturation and sedation scores were monitored intraoperatively for every 10 mins after the block was given and every $30 \mathrm{mins}$ for the first 2 hours postoperatively and then every $2 \mathrm{hrs}$ till $6 \mathrm{hrs}$ in to the postoperative period and thereafter every 6 hrs till 24 hrs postoperatively. The sensory block, the motor block and the pain scores were monitored every 2 hourly for the first 12 hrs then every 6 hourly till $24 \mathrm{hrs}$ postoperatively. If patient notice that block have wornedoff between the last assessment and present assessment, the time in which the patient noted block waning during this period was noted

Level of sedation was assessed using sedation scale ${ }^{16}$.

1-Calm, cooperative

2-Anxious but reassurable

3-Anxious and not reassurable

4-Crying or resisting
Duration of analgesia was defined as the time from injection of local anesthetic mixture to the use of rescue analgesic. Pain was assessed using the visual analog scale (0-10). The rescue analgesic (inj. Tramadol $100 \mathrm{mg}$ i.v.) was administered when the patient started complaining of pain (VAS Score $>4$ ).

Any complications pertaining to block technique or side effects of medications (if any) were also noted. After completion of study, the collected data was tabulated as mean \pm SD and compared by using software SPSS (15 Inc. version, Chicago). A p-value $<0.05$ was considered significant.

\section{Results}

The study was successfully conducted on 120 adult patients and all patients were included for data analysis. The demographic profile of the patients age, sex, weight, ASA grade were comparable in each group. (Table 1)

Time to sensory onset was significantly faster in group $\mathrm{RD}$ than group $\mathrm{R}[8.30 \pm 2.62 \mathrm{~min} v s .11 .50 \pm 3.14 \mathrm{mins}]$. The mean duration of sensory blockade was found to be significantly prolongedin patients of group RD compared to group R [1049.48 \pm 101.009 mins vs. $568.67 \pm$ 87.09 mins]. Addition of dexmedetomidine also significantly enhanced the duration of analgesia. The mean duration of analgesia in group $\mathrm{RD}$ was $1209.90 \pm 107.536$ mins while in group it was $784.60 \pm 88.12$ mins. (Table 2). Time to motor onset was also found to be significantly faster in group RD compared to group R [11.62 \pm 3.39 min vs 15.18 \pm 4.25 mins]. The mean duration of motor blockade was found to be significantly larger in group $\mathrm{RD}(895.37 \pm 61.62 \mathrm{mins})$ compared to group R (449.98 \pm 46.30 mins) Table 3.

The patients of group RD had significantly lower heart rates at all times intraoperatively and till 2 hours post operatively compared to patients of group R (Figure 1a). There was no statistically significant

Table 1: Demo graphics.

\begin{tabular}{|l|c|c|c|}
\hline & R (Mean \pm SD) & RD $($ Mean \pm SD) & p-value \\
\hline Age(years) & $35.38 \pm 13.537$ & $35.75 \pm 13.646$ & 0.88 \\
\hline Wt.(kgs) & $59.52 \pm 10.419$ & $60.27 \pm 9.107$ & 0.67 \\
\hline Gender(M/F) & $41 / 19$ & $43 / 17$ & 0.69 \\
\hline ASA(I/II) & $29 / 31$ & $28 / 32$ & 0.85 \\
\hline
\end{tabular}

${ }^{*} \mathrm{p} \leq 0.05$ - significant, $* * \mathrm{p} \leq 0.001$-highly significant.

Table 2: Sensory Block Characteristics.

\begin{tabular}{|l|l|l|l|}
\hline & R $($ Mean \pm SD) & RD $($ Mean \pm SD) & p-value \\
\hline Sensory onset (min) & $11.50 \pm 3.143$ & $8.30 \pm 2.625$ & $<0.001^{* *}$ \\
\hline Sensory duration (min) & $568.67 \pm 87.096$ & $1049.48 \pm 101.009$ & $<0.001^{* *}$ \\
\hline Duration of analgesia (min) & $784.60 \pm 88.121$ & $1209.90 \pm 107.536$ & $<0.001^{* *}$ \\
\hline
\end{tabular}

$* \mathrm{p} \leq 0.05$ - significant, $* * \mathrm{p} \leq 0.001$-highly significant.

Table 3: On set and duration of Motor Block.

\begin{tabular}{|l|l|l|l|}
\hline & R $($ Mean \pm SD) & RD $($ Mean \pm SD) & p-value \\
\hline Motor onset $(\min )$ & $15.18 \pm 4.257$ & $11.62 \pm 3.395$ & $<0.001^{* *}$ \\
\hline Motor duration $(\mathrm{min})$ & $449.98 \pm 46.302$ & $895.37 \pm 61.626$ & $<0.001^{* *}$ \\
\hline
\end{tabular}

$* \mathrm{p} \leq 0.05$ - significant, $* * \mathrm{p} \leq 0.001$-highly significant. 
Tiwari P (2015) A comparative clinical study of perineural administration of $0.75 \%$ ropivacaine with and without dexmedetomidinein upper limb surgery by ultrasound guided single injection supraclavicular brachial plexus block

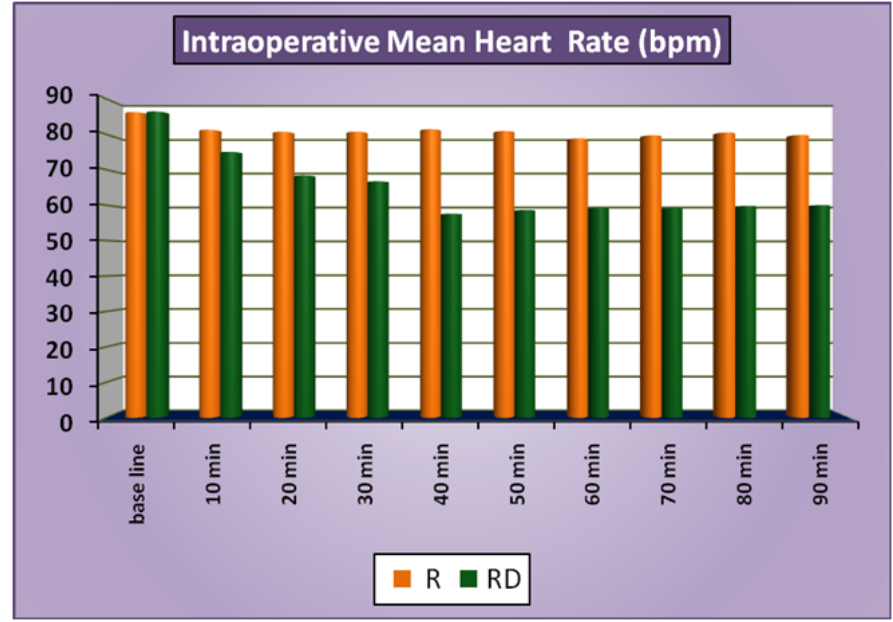

Figure 1a: Intraoperative Mean Heart Rate.

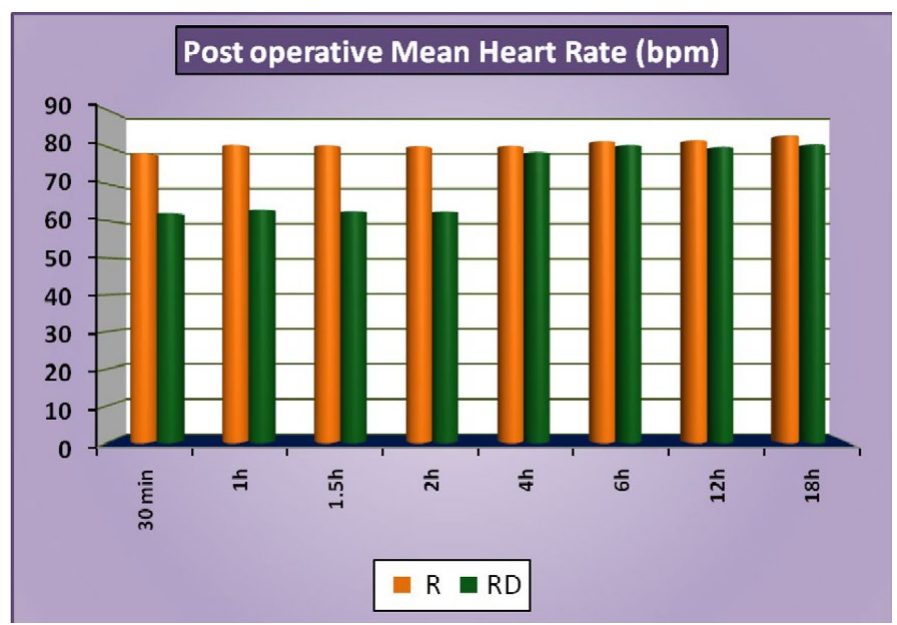

Figure 1b: Post-operative Mean Heart Rate.

difference in the post-operative heart rates between the two groups after the 2 hours. (Figure 1b) There was no statistically significant difference in the SBP between the two groups at baseline, intraoperatively or postoperatively (Figure $2 \mathrm{a}$ and $2 \mathrm{~b}$ ). No statistically significant difference was noted in the baseline DBP between the two groups. However, statistically significant and lower DBP were noted at $10 \mathrm{~min}$, $20 \mathrm{~min}, 30 \mathrm{~min}, 40 \mathrm{~min}, 50 \mathrm{~min}, 60 \mathrm{~min}$ and $70 \mathrm{~min}$ time intervals intraoperatively in group RD compared to group R (Figure 3a). No statistically significant difference was noted in the postoperative DBP values between the two groups. (Figure $3 \mathrm{~b}$ ) No significant difference was noted in the baseline MAP between the two groups. However, statistically significant \& lower MAP were noted at $10 \mathrm{~min}, 20 \mathrm{~min}, 30$ min, $40 \mathrm{~min}, 50 \mathrm{~min}, 60 \mathrm{~min}$ and $70 \mathrm{~min}$ time intervals intraoperatively in group $\mathrm{RD}$ compared to group $\mathrm{R}$ (Figure 4a). No statistically significant difference was noted in the postoperative MAP between the two groups. (Figure 4b) There was no significant difference in the baseline or intraoperative sedation scores between the groups.

No incidence of hypotension, respiratory depression (respiratory rate $<10$ breaths/min. or SPO $2<90 \%$ on air) or drowsiness (sedation) or any other study drug related side effects were noted in the two groups. However Bradycardia $(\mathrm{HR}<50 / \mathrm{min})$ was noted in 2 cases in $\mathrm{RD}$ group and none in group R. Bradycardia was treated with injection atropine $(0.2 \mathrm{mg}-0.6 \mathrm{mg} \mathrm{I} / \mathrm{V})$. There were no noted adverse effects associated with lower heart rates.

\section{Discussion}

When this study was designed, there were only a few clinical

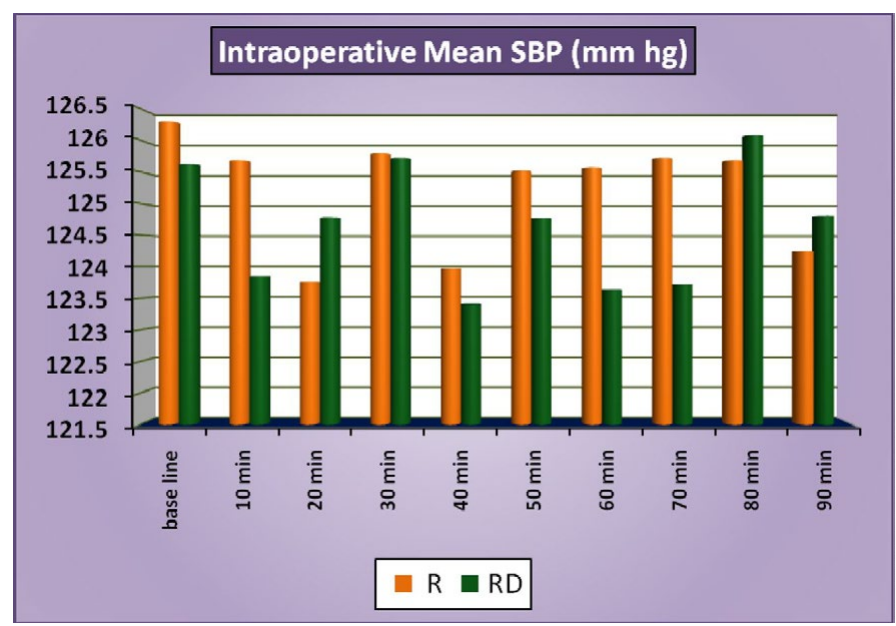

Figure 2a:Intraoperative Mean SBP.

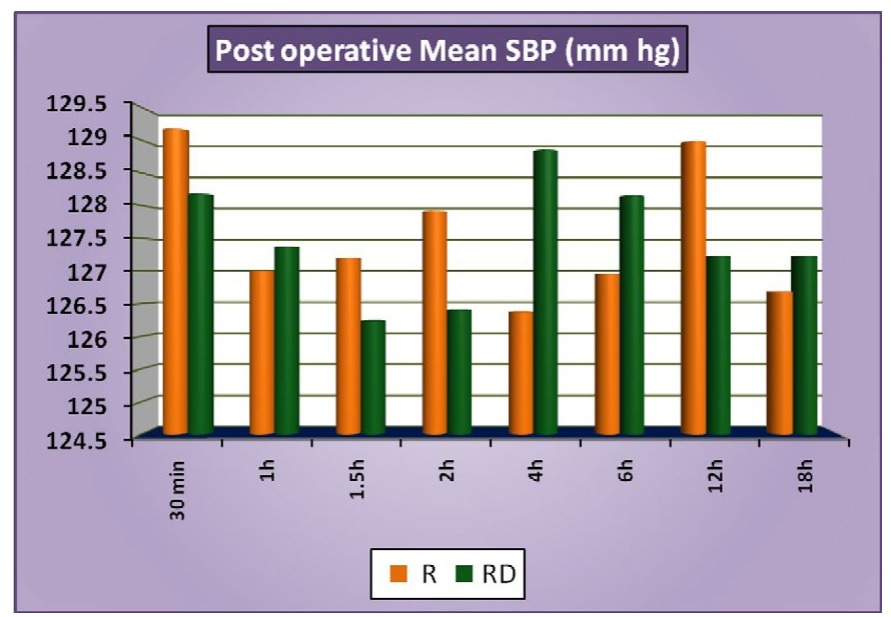

Figure 2b:Postoperative Mean SBP.

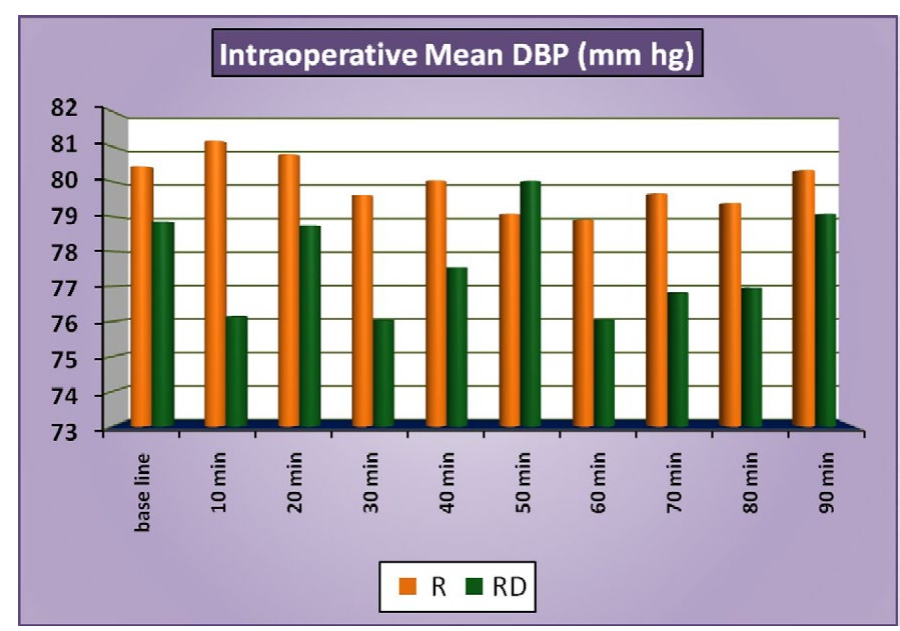

Figure 3a:Intraoperative Mean DBP. 
Tiwari P (2015) A comparative clinical study of perineural administration of $0.75 \%$ ropivacaine with and without dexmedetomidinein upper limb surgery by ultrasound guided single injection supraclavicular brachial plexus block

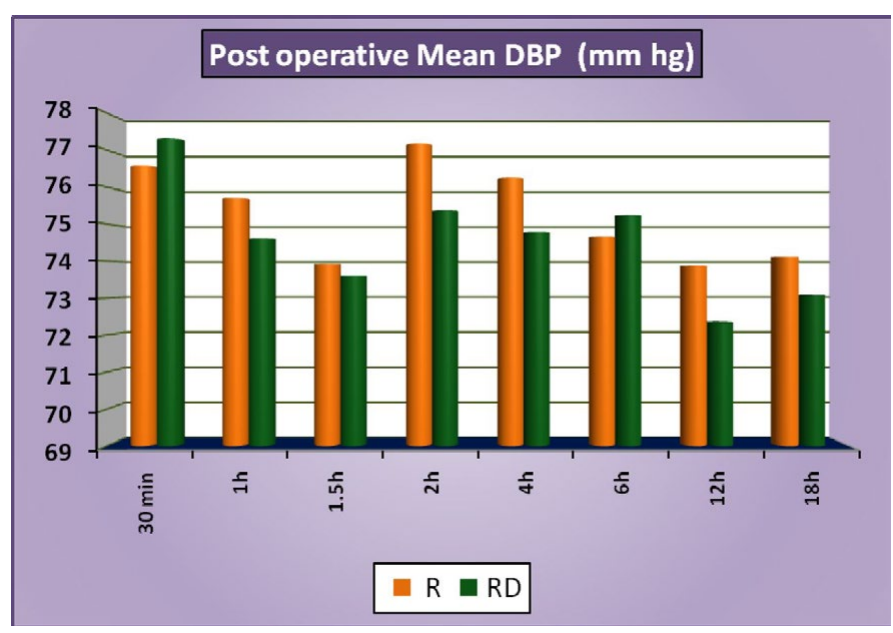

Figure 3b: Postoperative Mean DBP.

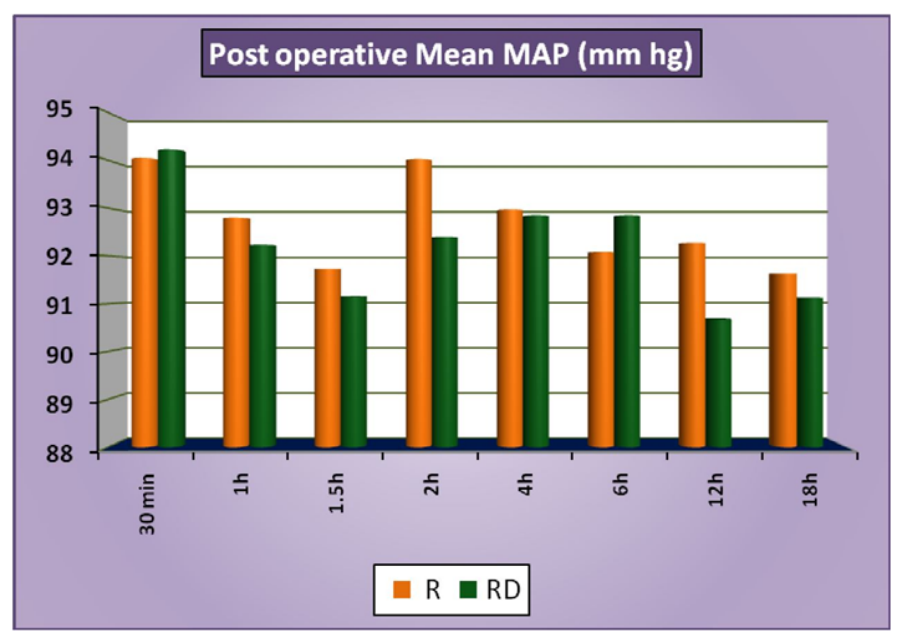

Figure 4a: Intraoperative Mean MAP.

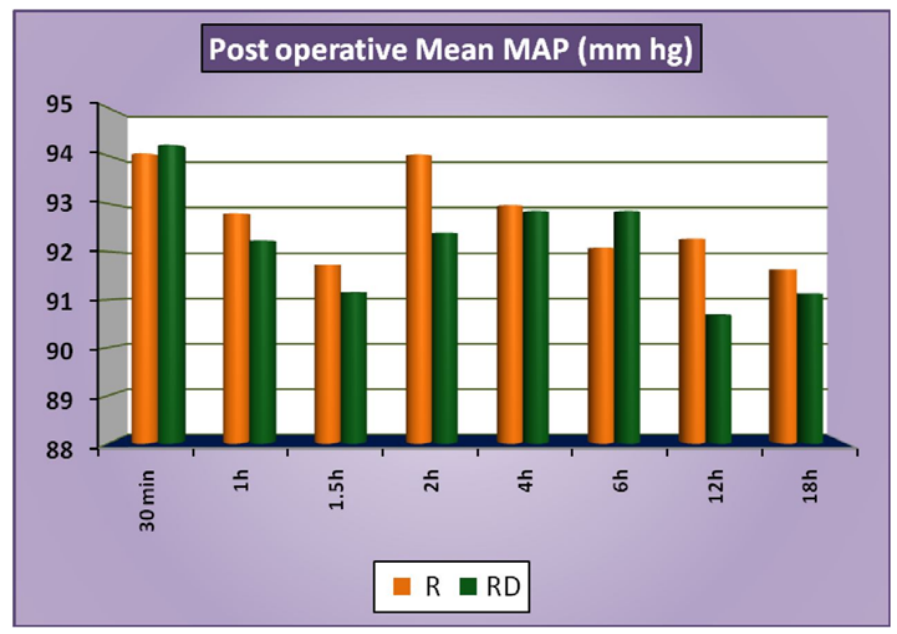

Figure 4b: Postoperative Mean MAP.

studies of peripheral perineural dexmedetomidine in humans and till date only a limited literature is available for peripheral use of perineural dexmedetomidine in humans in conjunction with ropivacaine exist. Among the many pharmacologic agents added to local anesthetics including opioids [4-8] and non-opioids [9-11] (midazolam,dexamethasone, ketamine), epinephrine has traditionally been added to local anaesthetic solutions to enhance the duration of analgesia and reduce the systemic absorption. Clonidine (a partial a 2 adrenoreceptor agonist) has been found to enhance and prolong the effect of ropivacaine for brachial plexus blockade [17]. Dexmedetomidine has selectivity 8 times more than clonidine for $a 2$ receptor ( $\alpha 2 / \alpha 1-1620: 1)$ [18-20].

Several hypothesized mechanism of action has been suggested to explain the analgesic effect of a 2 adrenoceptors agonists. Some of these include vasoconstriction around the injection site, direct suppression of impulse propagation through neurons as a result of a complex interaction of axonal ion channels or receptors, local release of encephalin- like substance, a decrease in localized inflammatory mediators and increase in anti-inflammatory cytokines through a a2adrenoceptors- mediated mechanism.

In present study a dosage of $50 \mu \mathrm{g}$ dexmedetomidine was chosen, based on the doses that have been proven safe for IV sedation [21] and on basis of data from previous studies that used dexmedetomidine intrathecally [19,22] (up to $10 \mu \mathrm{g}$ ) or perineurally [13] $(1 \mu \mathrm{g} / \mathrm{kg}$ ). An animal study showed that high-dose dexmedetomidine $(25-40 \mu \mathrm{g} / \mathrm{kg})$ on perineural administration did not damage axons or myelin sheaths and could even reduce the bupivacaine-induced acute perineural inflammation, thus highlighting safety of perineural dexmedetomidine [23]

In this prospective, randomized, double blind, controlled study adding $50 \mu \mathrm{g}$ dexmedetomidine to $19 \mathrm{ml}$ ropivacaine $0.75 \%$ for supraclavicular brachial plexus block shortens the sensory and motor block onset time, prolongs sensory and motor block duration and duration of analgesia and decreases the total analgesic requirement with no side effects. The mean duration of sensory and motor block were $1049.48 \pm 101.009$ mins. And $895.37 \pm 121$ mins respectively in dexmedetomidine plus ropivacaine group whereas duration of sensory and motor block was just $568.67 \pm 87.096$ mins and $449.98 \pm 46.302$ mins respectively in ropivacaine alone group. The duration of analgesia was significantly $(\mathrm{p}<0.001)$ longer in group dexmedetomidine plus ropivacaine group $(1209.90 \pm 107.536 \mathrm{mins})$ than in ropivacaine alone (784.60 \pm 88.121 mins).

Gerhard Fritsch et al. in their study compared $12 \mathrm{~mL}$ of $0.5 \%$ ropivacaine with $0.5 \%$ ropivacaine plus $150-\mu$ g dexmedetomidine for ultrasound-guided interscalene blocks and concluded that Dexmedetomidine added to ropivacaine for interscalene blocks increased the duration of the block and improved postoperative analgesia. These additional efficacy and safety data should encourage further study of peripheral perineural dexmedetomidine in humans. Dexmedetomidine group has significantly reduced heart rates compared to the control group. However they did not found any consistently significant differences in blood pressures between the groups [24].

Amany S. Ammar et al. in their clinical trial added dexmedetomidine to bupivacaine during placement of ultrasound guided infraclavicular block and they concluded that adding dexmedetomidine to bupivacaine enhanced onset and duration of sensory and motor block, prolonged duration of analgesia and yields lower VAS pain scores [25].

Esmaoglu et al. in their study added dexmedetomidine to levobupivacaine for an axillary brachial plexus block Dexmedetomidine added to levobupivacaine for axillary brachial plexus block shortens 
Tiwari P (2015) A comparative clinical study of perineural administration of $0.75 \%$ ropivacaine with and without dexmedetomidinein upper limb surgery by ultrasound guided single injection supraclavicular brachial plexus block

the onset time and prolongs the duration of the block and the duration of postoperative analgesia. Sometimes dexmedetomidine can cause bradycardia .They also explained that peripherally, $a 2$ receptor agonists produce analgesia by reducing release of norepinephrine and causing receptor-independent inhibitory effects on nerve fibre action potentials [14]. In another study D. Marhofer et al. added dexmedetomidine as an adjuvant to ropivacaine in patients undergoing ultrasound guided ulnar nerve block. They showed that addition of dexmedetomidine prolonged the duration of sensory and motor block and shortened the motor onset time although the time to sensory onset was not shortened [26].

Dexmedetomidine may also have side effects such as hypotension and bradycardia which usually occurs with increased dosage, along with other effects such as sedation and anxiolysis. Hemodynamic effects which occurs after perineural administration of dexmedetomidine possibly occurs due to some systemic uptake of the drug. The dexmedetomidine results in decreased systemic vascular resistance and indirectly decreased myocardial contractility, cardiac output, and systemic blood pressure. The decrease in heart rate caused by $\alpha-2$ agonist can also be explained on the basis of their central action by which they decrease sympathetic outflow and nor-epinephrine release.

\section{References}

1. Yang WT, Chui PT, Metreweli C (1998) Anatomy of the normal brachial plexus revealed by sonography and the role of sonographic guidance in anesthesia of the brachial plexus. AJR 171: 1631. [Crossref]

2. Kapral S, Krafft P, Eibenberger K, Fitzgerald R, Gosch M, Weinstabl C (1994) Ultrasound-guided supraclavicular approach for regional anesthesia of the brachial plexus. Anesth Analg 78: 507-513. [Crossref]

3. Ting PL, Sivagnanaratnam V (1989) Ultrasonographic study of the spread of local anaesthetic during axillary brachial plexus block. Br J Anaesth 63: 326-329. [Crossref]

4. Karakaya D, Büyükgöz F, Bariş S, Güldoğuş F, Tür A (2001) Addition of fentanyl to bupivacaine prolongs anesthesia and analgesia in axillary brachial plexus block. Reg Anesth Pain Med 26: 434-438. [Crossref]

5. Movafegh A, Nouralishahi B, Sadeghi M, Nabavian O (2009) An ultra-low dose of naloxone added to lidocaine or lidocaine-fentanyl mixture prolongs axillary brachial plexus blockade. Anesth Analg 109: 1679-1683. [Crossref]

6. Acharya R, Jena M, Mishra S, Rath SK (2014) Effect of butorphanol versus placebo as adjuvant to bupivacaine for supraclavicular brachial plexus blockade. Int J App Pharm 6: 8-10.

7. Bazin JE, Massoni C, Bruelle P, Fenies V, Groslier D, et al. (1997) The addition of opioids to local anesthetics in brachial plexus block: the comparative effects of morphine, buprenorphine and sufentanil. Anaesthesia 52: 858-862. [Crossref]

8. Robaux S, Blunt C, Viel E, Cuvillon P, Nouguier P, et al. (2004) 0Tramadol added to $1.5 \%$ mepivacaine for axillary brachial plexus block improves postoperative analgesia dose-dependently. Anesth Analg 98: 1172-1177. [Crossref]

9. Jarbo K, Batra YK, Panda NB (2005) Brachial plexus block with midazolam and bupivacaine improves analgesia. Can J Anaesth 52: 822-826. [Crossref]

10. Movafegh A, Razazian M, Hajimaohamadi F, MeysamieA (2006) Dexamethasone added to lidocaine prolongs axillary brachial plexus blockade. Anesth Analg 102: 263267. [Crossref]

11. Senel AC, Ukinc O, Timurkaynak A (2014) Does the addition of tramadol and ketamine to ropivacaine prolong the axillary brachial plexus block? Biomed Res Int: 686287. [Crossref]

12. Halaszynski TM (2012) Dexmedetomidine: A look at a promising new avenue of use. SJA 6: 104-106 [Crossref].

13. Obayah GM, Refaie A, Aboushanab O, Ibraheem N, Abdelazees M (2010) Addition of dexmedetomidine to bupivacaine for greater palatine nerve block prolongs postoperative analgesia after cleft palate repair. Eur J Anaesthesiol 27: 280-284. [Crossref]

14. Esmaoglu A, Yegenoglu F, Akin A, Turk CY (2010) Dexmedetomidine added to levobupivacaine prolongs axillary brachial plexus block. Anesth Analg 111: 15481551. [Crossref]

15. Borgeat A, Ekatodramis G, Dumont C (2001) An evaluation of the infraclavicular block via a modified approach of the Raj technique. Anesth Analg 93: 436-441. [Crossref]

16. Koroglu A, Demirbilek S, Teksan H, Sagır O, But AK, et al. (2005) Sedative, haemodynamic and respiratory effects of dexmedetomidine in children undergoing magnetic resonance imaging examination: preliminary results. Br J Anaesth 94: 821824. [Crossref]

17. El Saied AH, Steyn MP, Ansermino JM (2000) Clonidine prolongs the effect of ropivacaine for axillary brachial plexus blockade. Can J Anaesth 47: 962-967. [Crossref]

18. Yoshitomi T, Kohjitani A, Maeda S, Higuchi H, Shimada M, et al. (2008) Dexmedetomidine enhances the local anesthetic action of lidocaine via an alpha-2A adrenoceptor. Anesth Analg 107: 96-101. [Crossref]

19. Kanazi GE, Aouad M, Jabbour-Khoury SI, Al Jazzar MD, Alameddine MM, et al. (2006) Effect of low-dose dexmedetomidine or clonidine on the characteristics of bupivacaine spinal block. Acta Anaesthesiol Scand 50: 222-227. [Crossref]

20. Congedo E, Sgreccia M, De Cosmo G (2009) New drugs for epiduralanalgesia. Curr Drug Targets 10: 696-706. [Crossref]

21. Candiotti KA, Bergese SD, Bokesch PM, Feldman MA, Wisemandle W, et al. (2010) Monitored anesthesia care with dexmedetomidine: a prospective randomized, doubleblind, multicenter trial. Anesth Analg 110: 47-56. [Crossref]

22. Al-Mustafa MM, Abu-Halaweh SA, Aloweidi AS, Murshidi MM, Ammari BA, et al. (2009) Effect of dexmedetomidine added to spinal bupivacaine for urological procedures. Saudi Med J 30: 365-370. [Crossref]

23. Brummet CM, Norat MA, Palmisano JM, Lydic R (2008) Perineural administration of dexmedetomidine in combination with bupivacaine enhances sensory and motor blockade in sciatic nerve block without inducing neurotoxicity in rat. Anesthesiology 109: 502-511. [Crossref]

24. Fritsch G, Danninger T, Allerberger K, Tsodikov A, Felder TK, Kapeller M, et al (2014) Dexmedetomidine added to ropivacaine extends the duration of Interscalene Brachial Plexus Blocks for elective shoulder surgery when compared with ropivacaine alone. Reg Anesth Pain Med 39: 37-47. [Crossref]

25. Mahmoud KM, Ammar AS (2012) Ultrasound guided single injection infraclavicular brachial plexux block using bupivacaine alone or combined with dexmedetomidine for pain control in upper limb surgery:A prospective randomized controlled trial. Saudi $J$ Anaesth 6: 109-114. [Crossref]

26. Marhofer D, Kettner SC, Marhofer P, Pils S, Weber M, et al. (2013) Dexmedetomidine as an adjuvant to ropivacaine prolongs peripheral nerve block: a volunteer study. $\mathrm{Br} J$ Anaesth 110: 438-442. [Crossref]

Copyright: (C2015 Tiwari P. This is an open-access article distributed under the terms of the Creative Commons Attribution License, which permits unrestricted use, distribution, and reproduction in any medium, provided the original author and source are credited. 